doi:10.12662/2359-618xregea.v9i2.p88-100.2020

ARTIGOS

\section{O CONSUMO COLABORATIVO E A GERAÇÃO Y}

\section{THE COLLABORATIVE CONSUMPTION AND GENERATION Y}

\section{RESUMO}

O consumo colaborativo surge com a proposta de acesso a bens e serviços sem, necessariamente, a aquisição do produto ou a troca monetária para seu uso. Atualmente, existem vários modelos de negócios que estão ancorados nesse conceito, como compartilhamento de bicicletas e carros, hospedagem, sistema de caronas, espaços de trabalho etc. O presente estudo visa analisar como a geração y se relaciona com o consumo colaborativo, mediante uma pesquisa quantitativa e questionário aplicado por meio da ferramenta google for$m s$. Os dados foram analisados pelo software SPSS ${ }^{\circledast}$, utilizando as técnicas estatísticas média, desvio padrão e análise fatorial. Como resultado, constatou-se que existe uma predominância do gênero feminino, solteiros, com ensino superior incompleto/cursando, e que possuem conhecimento sobre o conceito de consumo colaborativo. Os fatores que mais influenciam no comportamento de consumo desses serviços são o financeiro e o socialmente responsável.

Palavras-chave: Consumo Colaborativo. Geração Y. Economia Compartilhada.

Sara Raquel de Melo Ferreira sara.ferreira@fatene.edu.br Mestre em Administração e Controladoria (UFC). Docente na Faculdade Tecnológica do Nordeste (FATENE). Fortaleza $-C E-B R$.

Érika de Araújo Ferreira erikaaraujo2010@gmail.com Graduada em Administração na Faculdade Terra Nordeste (FATENE). Fortaleza - CE$B R$.

Maria Gleiciene Rodrigues Oliveira gleicyenetbr@hotmail.com Graduada em Administração na Faculdade Terra Nordeste (FATENE). Fortaleza-CE$B R$.

\begin{abstract}
The collaborative consumption arises with the proposal of access to goods and services without necessarily purchasing the product or exchanging money for its use. Currently, there are several business models that are anchored in this concept, such as sharing bicycles and cars, lodging, hitchhiking, workspaces, etc. The present study aims to analyze how the generation y is related to the collaborative consumption, through a quantitative research and questionnaire applied through the google forms tool. The data were analyzed using SPSS software, using the statistical techniques mean, standard deviation and factorial analysis. As a result, it was found that there is a predominance of the female gender, unmarried, with incomplete / attending higher education, and who have knowledge about the concept of collaborative consumption. The factors that most influence the consumption behavior of these services are financial and socially responsible.
\end{abstract}


Keywords: Collaborative Consumption. Generation Y. Shared Economy.

\section{INTRODUÇÃO}

O consumo colaborativo tem ganhado força em todo o mundo, mas, no Brasil, tanto as iniciativas quanto os estudos ainda são incipientes (MENEZES, 2016). A autora afirma ainda que é sabido que as formas baseadas no aluguel ou empréstimo em vez da compra e venda não tratam de uma novidade; contudo, a Internet multiplicou e ampliou a maneira com que isso pode ser feito, pois uniu pessoas, por meio da tecnologia, com interesses em comum. Segundo o mesmo autor, conhecendo como o consumo colaborativo opera no Brasil, pode-se pensar em estratégias para seu estímulo e desenvolvimento, por parte da iniciativa pública, privada e da sociedade como um todo, de forma a favorecer seus aspectos positivos, que contribuem com a redução dos impactos do consumo excessivo, ampliam o acesso das pessoas a determinados produtos e serviços, permitindo maior interação entre os consumidores adeptos ao consumo colaborativo.

A essência do consumo colaborativo versa sobre práticas comerciais que possibilitam o acesso a bens e serviços sem que haja, necessariamente, a aquisição de um produto ou a troca monetária entre os envolvidos (BOTSMAN; ROGERS, 2011). Atualmente, é possível observar a formação de modelos de negócios que possuem o consumo colaborativo como base, como o compartilhamento de bicicletas, automóveis, espaços de trabalho (coworking), hospedagem, sistema de caronas (carona solidária) etc, muitas delas disseminadas por aplicativos on-line que facilitam e viabilizam o empréstimo, a troca e, até mesmo, a revenda desses produtos e serviços.

Além disso, o consumo colaborativo, ou a economia compartilhada como também é conhecido, é um fenômeno recente, que ainda está em formação e chega para modificar o paradigma do consumo atual, o qual é baseado na posse dos produtos, uma vez que esse conceito versa sobre o consumo consciente e o compartilhamento de produtos, fazendo que a posse passe a ser menos importante do que a experiência e sua utilização. Botsman e Rogers (2011) afirmam que a prática do consumo colaborativo não é uma tendência de nicho, ela é uma onda socioeconômica que está mudando a forma como as empresas entregam seus produtos e está mudando a forma como os consumidores satisfazem suas necessidades.

Atualmente, quando se aborda a economia e o consumo tradicionais, percebe-se que existe uma tendência de individualização que se acentua, à medida que o consumo torna os indivíduos pertencentes a um determinado grupo social, os quais estão, cada vez mais, em voga devido a plataformas digitais de comunicação que permitem a virtualização das comunicações, como afirma Mont (2004).

O consumidor que abraça a ideia do consumo colaborativo é mais consciente das consequências de seus atos de consumo e passa a atuar dentro da cadeia produtiva de fabricação, fazendo que seu papel não seja visto como o consumidor individual final (como é visto na economia tradicional), mas sim como parte integrante de uma coletividade que pode consumir determinado produto sem sua aquisição, fazendo que o compartilhamento amplie o uso do produto para mais pessoas (BOTSMAN; ROGERS, 2011).

Assim, percebe-se que as atitudes dos consumidores estão mudando. Atitudes que tendiam para a aquisição de bens e a compra de cada vez mais produtos estão gradativamente transformando-se em atitudes de compartilhamento, em que os indivíduos estão gerando ações coletivas. A posse passa a ser menos importante do que o uso do objeto, e a detenção dos produtos teve sua importância diminuída, e agora a experiência e o uso passam a ter importância maior para o consumidor. É importante ressaltar que, para a manutenção e expansão do conceito, existem obstáculos comportamentais, como o sentimento de posse e apego material, refletindo atitudes individualistas, as quais devem ser consideradas. 
Este estudo pretende investigar como a geração Y percebe o consumo colaborativo. A partir do questionamento exposto, esta pesquisa tem como objetivo geral analisar como a geração y se relaciona com o consumo colaborativo. Como objetivos específicos, têm-se: identificar o perfil da geração y; analisar o nível de conhecimento da geração y sobre o tema consumo colaborativo e verificar o relacionamento da geração y com os serviços e produtos disponibilizados por meio da prática de consumo colaborativo.

\section{FUNDAMENTAÇÃO TEÓRICA}

\subsection{CONSUMO COLABORATIVO}

Botsman e Rogers (2011) conceituam o consumo colaborativo como compartilhamento tradicional, escambo, empréstimo, negociação, locação, doação e troca, redefinido por meio da tecnologia e de comunidades entre pares, permitindo aos consumidores, além de perceber os benefícios enormes do acesso aos produtos e serviços em detrimento da propriedade, economizar dinheiro, espaço e tempo, fazer novos amigos, tornando-se cidadãos mais ativos.

Belk (2007) entende que o consumo pode ser compartilhado e descreve a atitude de sharing (compartilhar) como uma alternativa para a propriedade privada, transação financeira, troca e doação. No sharing, duas ou mais pessoas podem usufruir dos benefícios (ou dividir os custos) de possuir uma coisa.

Em vez de distinguir o que é meu e seu, sharing define algo como nosso, sendo uma forma alternativa de distribuição de mercadoria; e, em comparação com as formas mais tradicionais de distribuição, pode promover comunidade e economizar recursos. Um dos conceitos mais recentes para os usuários no Brasil é dado pelo site Consumo Colaborativo (2015, online) que entende como: "Prática comercial que possibilita o acesso a bens e serviços sem que haja necessariamente aquisição de um produto ou troca monetária entre as partes envolvidas neste processo. Compartilhar, emprestar, alugar e trocar substituem o verbo comprar no consumo colaborativo."

Menezes (2016) relata que o consumo colaborativo tem sido defendido por vários autores como uma alternativa para alcançar o desenvolvimento sustentável, ao passo que suplanta o estilo de hiperconsumo, criando sistemas inovadores fundamentados no compartilhamento.

Além disso, pode-se dizer que consumo colaborativo é aquele tipo de consumo promovido por organizações que se baseiam na colaboração de fornecedores e consumidores, mediada pelas tecnologias de informação e comunicação (MENEZES, 2016). Andrade e Pinto (2014) percebem o consumo colaborativo como uma série de práticas alternativas de consumo que possuem diferentes fins, mas que apontam para uma origem em comum: o ato de compartilhar.

Com o avanço e a disseminação das tecnologias de informação e comunicação, todas as pessoas que estão "conectadas" no mundo virtual estão suscetíveis a participar desse espaço colaborativo (MAURER et al., 2015). As propagandas começaram a promover, de forma criativa, a obsolescência percebida dos produtos e pregam que a compra de bens pode resultar em sentimentos de autoestima, liberdade, aventura e sucesso (MAURER et al., 2015).

O conceito de consumo colaborativo parece ser uma ideia inovadora, mas, na verdade, descreve um comportamento de uma prática tradicional já empregada pela humanidade desde as primeiras formas comerciais e que esteve em utilização até a emergência do modelo capitalista de produção, centrado na acumulação de riqueza e posse de mercadorias (MAURER et al., 2015).

Para Belk (2014), a velha sabedoria de que nós somos o que possuímos talvez tenha de ser modificada, considerando formas de posse e de uso que não envolvam propriedade. Assim, apesar de existir uma tendência à individualização e ao materialismo, os seres humanos possuem necessidades sociais e de pertencimento a grupos ou comunidades (MONT, 2004) que, com o passar do tempo, estão sendo substituídas por sociedades virtuais.

Maurer et al. (2015) afirma que as redes 
sociais são difusoras de um estilo de vida on -line e assumem um papel fundamental para a compreensão do contexto no qual as formas de consumo colaborativo estão inseridas. A internet possibilitou dinamicidade e amplitude às relações entre os indivíduos, facilitando a difusão de um modelo de consumo associado à colaboração. Belk (2014) enfatiza que, com a internet, existem muitas maneiras de expressar a identidade do indivíduo, mesmo sem possuir algo efetivamente. Nesse contexto, a internet mostra-se como um amplo espaço para compartilhamento de conteúdo, que pode ser obtido por qualquer pessoa que tenha acesso a ela. Porém, para Botsman e Rogers (2011), o consumo colaborativo não é uma tendência de nicho, tampouco uma reação passageira em lugares ainda em recessão; é uma onda socioeconômica que mudará o modo como a empresa encara sua proposta de valor, e como o consumidor satisfaz suas necessidades.

O compartilhamento faz um grande sentido prático e econômico para o consumidor, o meio ambiente e a comunidade. Também pode fazer uma grande dose de bom senso para os negócios que são suficientemente flexíveis, inovadores e com visão de futuro (BELK, 2014).

O consumo pode ser entendido como o processo que envolve desde o ato aquisitivo de bens e serviços, passando pela posse e o uso dele, pelo seu significado para os possuidores e não possuidores, até seu descarte. Não se trata apenas de consumo material ou imaterial. Trata-se também de consumo de símbolos, portanto, consumo cultural e social. E pode ser consumo político também (TASCHNER, 2010).

O consumo tornou-se um campo de investigação complexo, que engloba vários atores, atividades e um conjunto de bens e serviços que não necessariamente se restringem aos providos sob a forma de mercadorias. Dessa forma, o consumo engloba várias formas de provisão que não apenas as tradicionais formas de compra e venda de mercadorias em condições de mercado (BARBOSA; CAMPBELL, 2006 apud ANDRADE; PINTO, 2014).

Rocha (2002) afirma que os estudos aca- dêmicos privilegiam mais a produção do que o consumo. Isso, segundo o autor, se deve ao fato de que o consumo é, muitas vezes, visto como algo prejudicial, banal, por ser associado a aspectos negativos como o consumismo e a exclusão social que ele pode implicar em determinadas situações. E isso, segundo o autor, acontece tanto na opinião pública quanto entre os acadêmicos das ciências sociais e humanas.

Rocha (2002) aponta o consumo como um sistema de significação, e a principal necessidade social que supre é a necessidade simbólica, acrescentando que ele é como um código e, por meio dele, são traduzidas muitas das nossas relações sociais bem como elaboradas muitas das nossas experiências de subjetividade, e o consumo colaborativo passa a ser um caminho para uma mudança social.

Por fim, as participações nas atividades da economia compartilhada têm como motivo os fatores econômicos, ambientais e sociais e variam de acordo com a diversidade das atividades (SCHOR, 2014). Algumas pessoas participam visando a benefícios econômicos, como economizar dinheiro (BOTSMAN; ROGERS, 2011); algumas, visando à conquista de novos amigos (BOTSMAN; ROGERS, 2011); e outras são atraídas pelo modismo ou novidade das plataformas (SCHOR, 2014). Botsman e Rogers (2011) afirmam que a economia compartilhada resgata comportamentos naturais dos seres humanos, como o compartilhamento e a troca, os quais podem ter seu potencial aumentado por meio de interações via Internet.

\subsection{GERAÇÃO Y}

Dutra (2010, p. 209) afirma que a geração pode ser entendida como um grupo de "[...] pessoas que compartilha um período de anos de nascimento e eventos históricos significativos ao longo de suas vidas [...] além de um conjunto de valores, atitudes, preferências e comportamentos semelhantes [...]". Esses compartilhamentos ajudam os integrantes de cada geração a interpretar as experiências de vida, como ainda afirma o autor. 
Veloso, Dutra e Nakata (2016) apontam que não existe uma pacificação na literatura quanto aos períodos que definem onde começa e onde termina cada uma das gerações. Porém, ainda segundo os autores, apesar da divergência de períodos, as características de cada geração não são divergentes. Atualmente, existem três gerações: baby boomers, geração $\mathrm{X}$ e geração Y (VELOSO; DUTRA; NAKATA, 2016).

Os membros da geração $\mathrm{Y}$, geração foco desta pesquisa, são aqueles nascidos entre 1978 até os dias de hoje e já cresceram em um mundo conectado, em que a informação está disponível a todos; porém, apresentam características mais individualistas (VELOSO; DUTRA; NAKATA, 2016). Justamente por isso essa geração também é conhecida como geração Net ou geração N. Esses indivíduos valorizam o equilíbrio pessoal e profissional e fazem questão de exprimir suas opiniões (DUTRA, 2010). Segundo Rudge et al. (2017), essa geração foi a primeira a compartilhar comportamentos, independentemente da localidade onde elas estavam, justamente pelo fato de ser a primeira geração inserida no processo de globalização e conectividade. Além disso, são indivíduos multitarefas, isto é, escutam música no celular ao mesmo tempo em que assistem à televisão e buscam informações no computador (SOLOMON, 2016).

Garbin (2003) afirma que outra característica dessa geração é a existência de objetivos mais imediatistas, como prazer e consumo de bens materiais, além da preferência pelo convívio virtual ao real. Sobre o consumo, Solomon (2016) afirma que os consumidores da geração $Y$ não são leais às marcas como as demais gerações o são e tendem a comprar por impulso. Por fim, Dutra e Dutra (2016) afirmam, ainda, que as pessoas que fazem parte da geração Y são generosas e intransigentes com incoerências e inconsistências, possuindo um senso de justiça acentuado.

\section{METODOLOGIA}

Esta pesquisa foi desenvolvida na forma de um estudo natureza quantitativa. A pesquisa quantitativa, como afirmam Richardson et al. (2012), caracteriza-se pelo emprego de métodos de quantificação para a coleta e o tratamento das informações, uma vez que o tratamento se dá por meio de técnicas estatísticas que podem ser mais simples (percentual, média, desvio padrão etc.) até as mais complexas, como correlação e análise fatorial. Além disso, o autor afirma que o método quantitativo possui a intenção de garantir a precisão dos resultados, evitando distorções de análise e de interpretação, comuns em pesquisas de natureza qualitativa.

As pesquisadoras adaptaram o questionário de Pizzol (2015) e aplicaram-no, via google forms, a uma amostra por conveniência de 169 indivíduos, a qual foi identificada a partir de grupos da rede social Facebook. No entanto, como se buscava pesquisar apenas a geração Y, isto é, indivíduos nascidos de 1978 até os dias atuais, conforme Veloso, Dutra e Nakata (2016), a amostra foi reduzida para 144 indivíduos. Os dados coletados foram analisados por meio do software SPSS ${ }^{\circledR}$, utilizando-se as técnicas de média, desvio padrão, frequência e análise de fatores ou análise fatorial.

Bussab e Morettin (2002) afirmam que o conceito de média é um dos conceitos mais familiares, que é definido como a soma das observações dividida pelo número de ocorrência delas. Já o desvio padrão, segundo Field (2009), é uma estimativa de "espalhamento" médio do conjunto de dados mensurados, sendo a medida que representa o quão bem a média representa os dados. Assim, quando ocorrem pequenos desvios padrões, isso indica que os dados analisados estão próximos da média, e um desvio padrão grande indica que os dados analisados estão distantes da média.

Ainda segundo Field (2009), a análise de fatores é uma técnica que identifica grupos ou agrupamentos de variáveis, servindo para entender a estrutura de um conjunto de variáveis, construir ou validar um questionário para a medição de uma variável e reduzir um conjunto de dados a um tamanho analisável, sem a perda das informações coletadas. O autor complementa afirmando que a análise de fatores reduz as 
variáveis, aglomerando-as de acordo com suas similaridades. Assim, as variáveis de um mesmo grupo são similares entre si e diferentes das outras variáveis de um segundo grupo, sugerindo que elas podem medir os mesmos aspectos dentro de uma dimensão estudada. Figueiredo Filho e Silva Júnior (2010) complementam afirmando que uma mesma variável não pode contribuir para a construção de fatores distintos, e o limite aceitável de contribuição da variável na criação do fator é de 0,40 . Valores abaixo disso devem ser evitados, uma vez que podem apresentar problemas de indeterminação de variáveis nos fatores propostos.

Após a análise fatorial das questões da segunda sessão do questionário, a qual era constituída de afirmações que mediam a concordância e discordância do respondente por meio de uma escala likert, as pesquisadoras excluíram da análise as perguntas " 38 . Eu valorizo não precisar me preocupar com os horários do transporte coletivo (ônibus, metrô, etc) para meus deslocamentos de rotina." e "39. Prefiro a liberdade de ter meu próprio meio de transporte a qualquer momento, do que um horário limitado para uso da (o) bicicleta / carro compartilhado." uma vez que elas não apresentaram similaridade com nenhuma pergunta de nenhum dos quatro fatores identificados.

\section{RESULTADOS}

A primeira pergunta do instrumento de coleta de dados versava sobre qual o local de residência dos pesquisados. A região metropolitana de Fortaleza foi a mais citada, representando 56,9\% (82 respondentes), seguida da cidade de Fortaleza com 36,1\% (52 respondentes). As cidades de Mossoró (RN), Iguatu (CE) e São Paulo (SP) foram citadas também, mas com menor representatividade. Como a metodologia da pesquisa utilizou uma amostragem por conveniência, não se pode tirar conclusões sobre esse dado, servindo apenas para se ter ciência de onde os respondentes moram.

Quanto ao gênero dos respondentes, $56,2 \%$ afirmaram ser do sexo feminino (81 res- pondentes), enquanto que $43,8 \%$ (63 respondentes) afirmaram ser do gênero masculino. Sobre o estado civil, 66,7\% (98 respondentes) informaram ser solteiros; $24,3 \%$ (35 respondentes) afirmaram ser casados; 4,9 (7 respondentes) informaram ser divorciados e 4,2\% (6 respondentes) informaram viver em uma união estável.

Quando os respondentes foram questionados sobre sua escolaridade, $56,9 \%$ (82 respondentes) afirmaram possuir ensino superior incompleto/cursando; $18,1 \%$ (26 respondentes) possuem ensino superior completo e 13,9\% (20 respondentes) informaram possuir pós-graduação, conforme pode ser verificado no gráfico 1. Esse achado se aproxima do resultado apontando por Ferreira e Lima (2018), em que 35\% dos seus respondentes apontaram ter ensino superior incompleto/cursando. Porém, afastam-se Arruda et al. (2016), uma vez que $84 \%$ dos respondentes desta pesquisa afirmaram ter ensino superior completo.

Gráfico 1 - Escolaridade

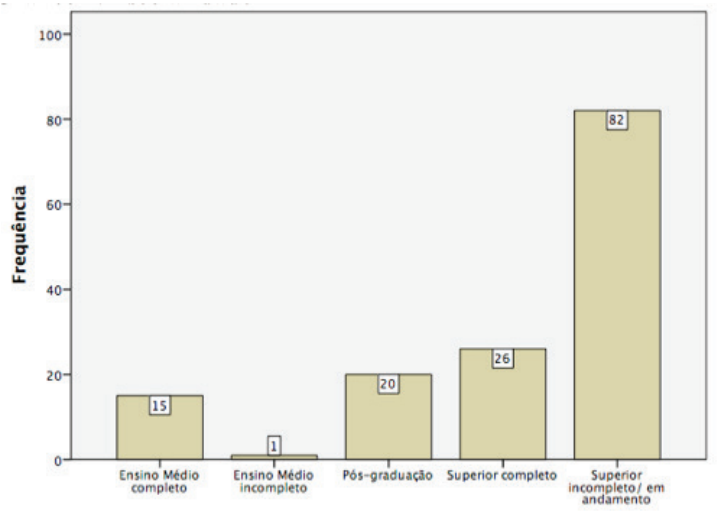

Fonte: dados da pesquisa (2018).

Quando os respondentes foram questionados sobre sua renda, 52,1\% (75 respondentes) afirmaram receber salários de até $\mathrm{R} \$$ $1.500,00$, seguido de $36,8 \%$ (53 respondentes) que afirmaram receber entre $\mathrm{R} \$ 1.501,00$ e $\mathrm{R} \$$ $4.000,00$, conforme gráfico 2. Pode-se inferir desse resultado que muitos indivíduos pesquisados que fazem parte da geração $\mathrm{Y}$ ainda estão cursando ensino superior, e sua renda é proveniente de estágio. 
Gráfico 2 - Renda

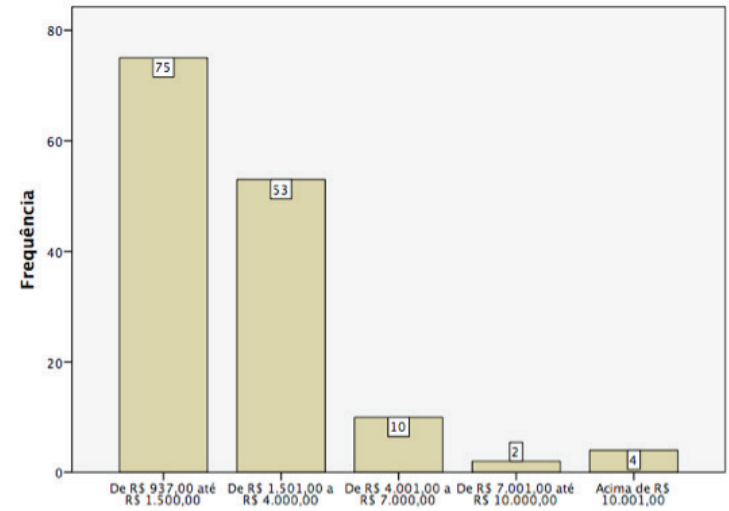

Fonte: dados da pesquisa (2018).

Os respondentes foram questionados diretamente se tinham conhecimento sobre o conceito de consumo colaborativo e se tinham ciência de que os serviços pesquisados são práticas comerciais que fazem parte do conceito. Verificou-se que 51,3\% (74 respondentes) dos respondentes afirmaram que conhecem o conceito, e $61,8 \%$ (93 respondentes) declararam que sabiam que os serviços aqui pesquisados fazem parte do conceito de consumo colaborativo. Esse resultado aponta que os indivíduos da geração y que participaram desta pesquisa até sabem que a bicicleta e o carro compartilhados, por exemplo, são produtos compartilhados, mas não sabem ao certo o que esse conceito significa. Belk (2014) aponta que existe um comportamento positivo dos indivíduos em relação aos serviços da economia compartilhada, porém questões comportamentais, com sentimento de posse, ainda interferem no uso dos serviços compartilhados. Acredita-se que é necessária uma maior divulgação dos benefícios do compartilhamento (redução da emissão de gases combustíveis e redução dos custos de fabricação, por exemplo) para que mais pessoas, inclusive as que apontaram não conhecer os serviços ofertados, passem a utilizá-los.

A fim de identificar o nível de conhecimento dos serviços que fazem parte do conceito de consumo colaborativo, os respondentes foram questionados sobre a utilização e o conhecimento dos serviços de carona solidária, aluguel de casa ou apartamento para turismo; bicicleta compartilhada, carro compartilhado, coworking e site de troca de serviços.

Quando questionados sobre a utilização da carona solidária, 57,6\% (83 respondentes) afirmaram "Nunca utilizei, mas tenho conhecimento", seguido de $17,4 \%$ (25 respondentes) afirmaram que "Nunca utilizei e não tenho conhecimento", conforme pode ser verificado no gráfico 3. Do total de respondentes que informaram que utilizam o sistema de carona solidária (36 respondentes), 50\% (18 respondentes) informaram que utilizam com a finalidade de se locomover para o trabalho. As demais finalidades apontadas foram: lazer, locomoção para escola/faculdade, viagens e afazeres da rotina.

Gráfico 3 - Utilização de carona solidária

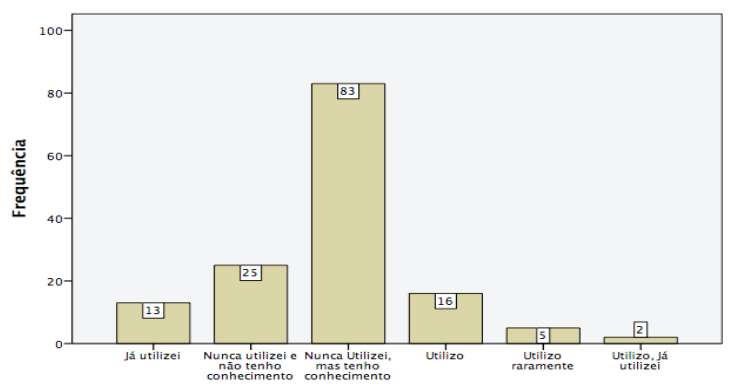

Fonte: dados da pesquisa (2018).

Quando questionados sobre a utilização de aluguel de casa ou apartamento para turismo, 54,9 (79 respondentes) afirmaram "Nunca utilizei, mas tenho conhecimento", seguido de 16,7\% (24 respondentes) que afirmaram “Já utilizei" e 13,9 (20 respondentes) afirmaram que "utilizo", conforme gráfico 4.

Gráfico 4 - Utilização de aluguel de casa ou apartamento para turismo

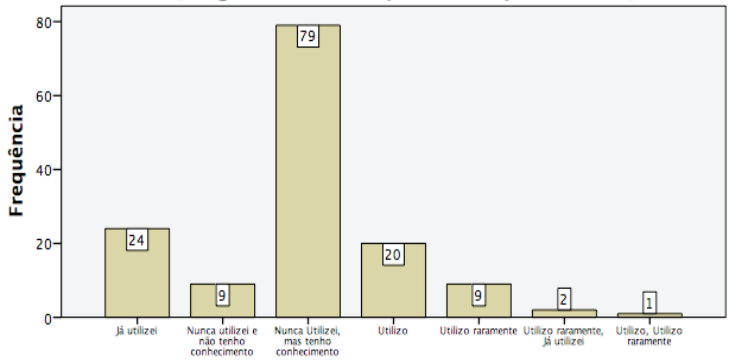

Fonte: dados da pesquisa (2018). 
Quando questionados sobre a utilização de bicicletas compartilhadas, 70,8\% (102 respondentes) afirmaram "Nunca utilizei, mas tenho conhecimento", seguido de 11,8\% (17 respondentes) que afirmaram "utilizo", conforme pode ver verificado no gráfico 5 . Do total de respondentes que informaram que utilizam o sistema de bicicletas compartilhadas (32 respondentes), 90\% (29 respondentes) informaram que utilizam com a finalidade de lazer.

Gráfico 5 - Utilização de bicicletas compartilhadas

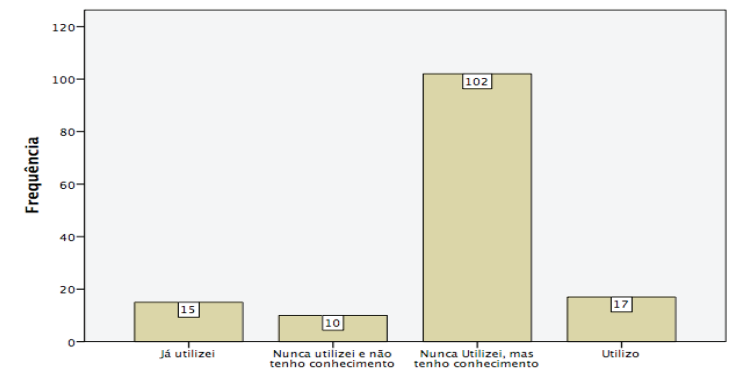

Fonte: dados da pesquisa (2018).

Quando questionados sobre a utilização de carro compartilhado, 80,6\% (116 respondentes) afirmaram "Nunca utilizei, mas tenho conhecimento", seguido de 9,7\% (14 respondentes) afirmaram que "Nunca utilizei, mas não tenho conhecimento", conforme pode ser verificado no gráfico 6 .

Gráfico 6 - Utilização de carros compartilhados

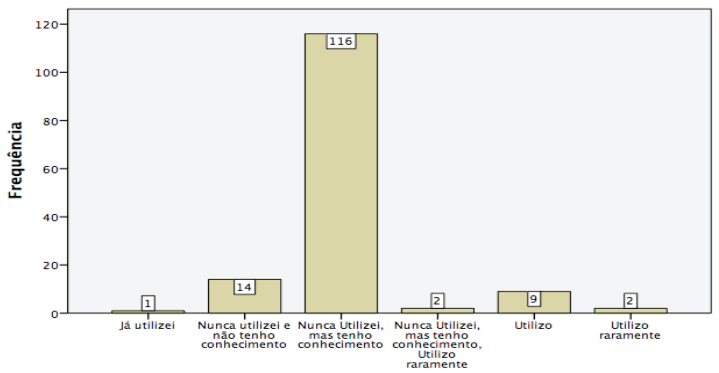

Fonte: dados da pesquisa (2018).

Quando questionados sobre a utilização de coworking, 66\% (95 respondentes) afirmaram "Nunca utilizei, mas tenho conhecimento", seguido de $28,5 \%$ (41 respondentes) afirmaram que "Nunca utilizei e não tenho conhecimento", conforme gráfico 7 .
Gráfico 7 - Utilização de coworking

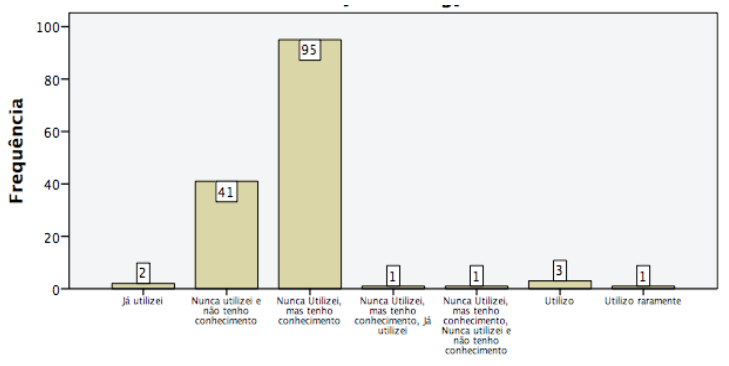

Fonte: dados da pesquisa (2018).

E quando questionados sobre a utilização de sites de trocas de serviços, 58,3\% (84 respondentes) afirmaram "Nunca utilizei, mas tenho conhecimento", seguido de 13,9\% (20 respondentes) afirmaram que "Nunca utilizei e não tenho conhecimento" e 13,2\% (19 respondentes) afirmaram que "utilizo", como pode ser visualizado no gráfico 8 .

Gráfico 8 - Utilização de sites de trocas de serviços

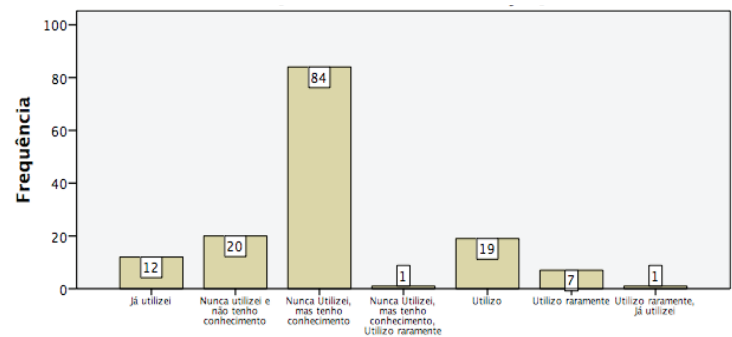

Fonte: dados da pesquisa (2018).

Observa-se que, apesar dos respondentes afirmarem ter conhecimento das práticas de consumo colaborativo, elas são pouco utilizadas nas rotinas dos indivíduos pesquisados. Em todos os serviços pesquisados, observa-se que há o conhecimento da existência do serviço, mas a maioria dos respondentes opta por não utilizá -los. Belk (2014) pontua que questões comportamentais, como sentimentos de posse e apego aos bens materiais podem interferir no uso dos serviços da economia compartilhada, uma vez que não existe a posse dos produtos, apenas seu uso. Já Ferreira e Lima (2018) apontam que um dos motivos para a utilização dos serviços compartilhados seriam as motivações econômicas e socioambientais, uma vez que os usuários não compram o produto, o que ocasiona economia 
para o indivíduo, e seu uso tem menor impacto ambiental, ou seja, polui menos. Observa-se que, para os indivíduos aqui pesquisados, as motivações econômicas e socioambientais pouco influenciam os indivíduos a optarem pelos serviços compartilhados disponíveis.

A segunda sessão do instrumento de coleta de dados visava investigar mais a fundo o nível de conhecimento dos respondentes sobre o conceito. Utilizando a técnica estatística análise fatorial, foi possível identificar quatro fatores: financeiro, comodidade, relacionamento e confiabilidade e socialmente responsável.

Ao analisar as afirmações que fazem parte do fator financeiro, identificou-se que os respondentes concordam com as afirmativas "A utilização dos serviços de compartilhamento possibilita a redução dos custos" e "Participar de qualquer atividade de compartilhamento me beneficia financeiramente", ambos com média maior que 4. Porém, a afirmação "Utilizo o compartilhamento de bicicletas / carros e carona solidária porque é mais barato do que outros meios de transporte" a média das respostas foi nem con- cordo nem discordo $(3,50)$, além de ter possuído o maior desvio padrão $(1,27)$, significando que houve muita dispersão entre as respostas dadas, conforme pode ser verificado na tabela 1 . Além disso, a tabela aponta ainda as cargas fatoriais das afirmações, as quais são consideradas altas (maior que 0,40 ) confirmando que as perguntas fazem parte de um mesmo fator.

Esse resultado aponta que, mesmo tendo ciência da economia financeira alcançada com o uso da economia compartilhada, os usuários preferem não utilizá-la. O fator financeiro não tem poder de convencimento suficiente a ponto de fazer que o usuário deixe seu carro em casa e utilize a bicicleta ou, até mesmo, o carro compartilhado.

Arruda et al. (2016) apontaram em seu estudo que a economia de tempo e dinheiro é a principal motivação para o uso de bicicletas compartilhadas. Neste estudo, vê-se que a economia monetária não pode ser apontada como uma motivação de uso, apesar de esse fato ser conhecido pelos participantes da pesquisa.

Tabela 1 - Fator financeiro

\begin{tabular}{lccc}
\hline & Carga fatorial & Média & Desvio Padrão \\
\hline $\begin{array}{l}\text { 34. A utilização dos serviços de compartilhamento } \\
\text { possibilita a redução dos custos. }\end{array}$ &, 813 & 4,2 &, 93 \\
$\begin{array}{l}\text { 35. Participar de qualquer atividade de compartilhamento } \\
\text { me beneficia financeiramente. }\end{array}$ &, 909 & 4,0 &, 99 \\
$\begin{array}{l}\text { 36. Utilizo o compartilhamento de bicicletas / carros e } \\
\text { carona solidária porque é mais barato do que outros } \\
\text { meios de transporte }\end{array}$ &, 692 & 3,5 & 1,27 \\
\hline
\end{tabular}

Fonte: dados da pesquisa (2018).

O segundo fator identificado foi comodidade, composto por itens que visam investigar o conforto e a confiabilidade dos serviços da economia compartilhada. Esse fator era composto por seis itens, e, para cinco deles, a média de resposta foi entre 3,2 e 3,7, significando que os respondentes nem discordaram da afirmação e nem concordaram. O ponto que chama a atenção nesse fator é o item que questiona se os respondentes sabem que não possuem a posse dos bens, sendo claro para os participantes da pesquisa que os bens não são comprados e que eles pagam pelo seu uso.

Observa-se, ainda, certa desconfiança com as condições de uso dos bens compartilhados, assim como a impossibilidade de utilizar o bem quando o consumidor necessita, sendo que esses achados corroboram o que Chase (2015) afirma. Segundo a autora, a ênfase na posse dos produtos possui bases no medo da escassez. Assim, os indivíduos escolhem comprar os produtos, pois temem que, quando necessitarem utilizá-los, não terão acesso. Pode-se justificar esse achado com base no perfil da amostra do 
estudo. Esta pesquisa concentrou-se em indivíduos da geração y, que, conforme Veloso, Dutra e Nakata (2016), apesar de os componentes dessa geração terem crescido em um mundo conectado, eles ainda apresentam características individualistas e possuidores de objetivos imediatistas, como o consumo de bens materiais, acrescenta Garbin (2003).

Por fim, as cargas fatoriais, médias e desvios padrão de todos os itens que fazem parte desse fator podem ser observados na tabela 2 .

Tabela 2 - Fator comodidade

\begin{tabular}{lccc}
\hline & Carga fatorial & Média & Desvio Padrão \\
\hline $\begin{array}{l}\text { 37. Eu sei que quando uso bicicletas e carros compartilhado, } \\
\text { assim como aluguéis de roupas, eu não tenho a propriedade } \\
\text { desses bens (tenho que devolver após o uso). }\end{array}$ &, 510 & 4,5 &, 8662 \\
$\begin{array}{l}\text { 41. Utilizar a(o) bicicleta / carro compartilhado me poupa } \\
\text { tempo. }\end{array}$ &, 594 & 3,3 & 1,16 \\
$\begin{array}{l}\text { 42. Eu aprecio a comodidade de utilizar a(o) bicicleta / carro } \\
\text { compartilhado nos deslocamentos que eu realizo. }\end{array}$ &, 698 & 3,2 & 1,22 \\
$\begin{array}{l}\text { 44. Eu confio no modelo de operação do compartilhamento } \\
\text { de bicicletas / carros. }\end{array}$ &, 676 & 3,2 & 1,07 \\
$\begin{array}{l}\text { 49. Eu temo não poder utilizar a(o) bicicleta / carro } \\
\text { compartilhado na hora em que eu precisar usá-lo. }\end{array}$ &, 669 & 3,5 & 1,14 \\
$\begin{array}{l}\text { 50. Eu temo que a(o) bicicleta / carro não esteja em } \\
\text { condições de uso (manutenção, limpeza) na hora em que } \\
\text { eu precisar utilizá-lo. }\end{array}$ &, 646 & 3,7 & 1,05 \\
\hline
\end{tabular}

Fonte: dados da pesquisa (2018).

Ao analisar as afirmações que fazem parte do fator relacionamento e confiabilidade, identificou-se que os respondentes não concordam nem discordam das afirmações. Com base nos dados da tabela 3 , infere-se que os usos dos serviços de compartilhamento não influenciam no relacionamento de seus usuários ou na construção de novos laços de amizade ou contatos profissionais (networking). Juntamente com o fator comodidade, o fator relacionamento apresentou as menores cargas fatoriais, médias e maiores desvios padrão. Infere-se que esse re- sultado pode ser derivado da baixa utilização dos serviços que fazem parte do conceito de consumo compartilhado.

Para Chase (2015), as pessoas estão no centro da economia compartilhada e, para que ela prospere cada vez mais, o relacionamento e a confiabilidade são bases necessárias e importantes para o conceito. $\mathrm{O}$ achado deste estudo não se coaduna com o que afirma o autor, porém acredita-se que, com o aumento da utilização dos serviços compartilhados, essa relação possa mudar.

Tabela 3 - Fator relacionamento e confiabilidade

\begin{tabular}{lcccc}
\hline & Carga fatorial & Média & Desvio Padrão \\
\hline 40. A utilização do serviço de carona solidária me permite &, 537 & 3,917 & 1,0276 \\
fazer novos amigos, economizar e ajudar o meio ambiente. & & 3,722 & 1,0607 \\
$\begin{array}{l}\text { 43. Usar o compartilhamento bicicletas, carros e coworking } \\
\text { ou sites de troca de serviços e produtos me permite fazer } \\
\text { parte de um grupo de pessoas com interesses semelhantes. }\end{array}$ & & & &
\end{tabular}


45. Eu confio nos serviços de compartilhamento de bicicletas / carros que eu utilizo.

46. Eu confio nos membros que participam do programa de compartilhamento de bicicletas e carros, assim como nos de sites de trocas e serviços de produtos.

47. O serviço de compartilhamento de bicicletas / carros é seguro.

48. O serviço de compartilhamento de coworking me permite trabalhar o networking com diversas pessoas de todas as áreas profissionais e ainda me ajuda na redução de custo.

$\begin{array}{lll}, 736 & 3,188 & 1,1092 \\ & & \\ , 842 & 3,000 & 1,0967 \\ & & \\ , 809 & 3,097 & 1,0533 \\ , 727 & 3,569 & 1,0488\end{array}$

, 626

53. Usar algum dos serviços de compartilhamento melhora a minha imagem perante a comunidade e a sociedade

Fonte: dados da pesquisa (2018).

Por fim, ao analisar as afirmações que fazem parte do fator socialmente responsável, identificou-se que os respondentes concordam que as práticas de consumo colaborativo reduzem o consumo de recursos naturais, e que seu uso significa pensar no meio ambiente, conforme pode ser verificado na tabela 4 . Esse achado corrobora Arruda et al. (2016), no sentido de que os usuários dos serviços compartilhados estão preocupados com o meio ambiente e apoiam, utilizam meios e ferramentas que reduzam o consumo de recursos naturais, que poluam menos e que gerem menos resíduos.

Além disso, Chase (2015) também aponta que, na economia compartilhada, não é necessário expandir a produção para gerar mais consumo, basta conectar os indivíduos que possuem bens ociosos para fazer que esses produtos possam circular e serem utilizados por outras pessoas.

Tabela 4 - fator socialmente responsável

\begin{tabular}{lccc}
\hline & Carga fatorial & Média & Desvio Padrão \\
\hline $\begin{array}{l}\text { 51. A prática do consumo colaborativo reduz o consumo } \\
\text { dos recursos naturais. }\end{array}$ &, 894 & 4,111 &, 9902 \\
$\begin{array}{l}\text { 52. Eu me sinto bem quando compartilho recursos e } \\
\text { evito o consumo excessivo. }\end{array}$ &, 873 & 3,951 & 1,0127 \\
$\begin{array}{l}\text { 54. Utilizar produtos e serviços por meio do } \\
\text { compartilhamento solidário significa pensar em prol } \\
\text { do meio ambiente. }\end{array}$ & & 4,899 & 1,0185 \\
\hline
\end{tabular}

Fonte: dados da pesquisa (2018).

Por fim, Arruda et al. (2016) complementam que as bicicletas compartilhadas são bastante utilizadas por serem formas de locomoção limpas, demostrando uma preocupação com o meio ambiente.

\section{CONSIDERAÇÕES FINAIS}

Por meio dos questionamentos propostos no instrumento de coleta de dados utilizados neste estudo, pode-se responder aos objetivos específicos propostos. Como resposta ao primeiro objetivo específico (identificar qual o perfil da geração y), a pesquisa apontou, com base na amostra utilizada, que existe uma predominância do gênero feminino, solteiros, com ensino superior incompleto/cursando, que moram em Fortaleza e região metropolitana, e que possuem renda de até $\mathrm{R} \$ 1.500,00$. Esses jovens utilizam seus smartphones para se conectarem com outros jovens, mas também com os serviços da economia compartilhada, e possuem grande facilidade com aparatos tecnológicos, pois já nasceram em um mundo conectado. 
Em resposta ao segundo objetivo específico (analisar o nível de conhecimento da geração y sobre o tema consumo colaborativo), a pesquisa apontou que uma parte da amostra $(51,3 \%)$ possui conhecimento sobre o conceito, e que a maioria $(61,3 \%)$ sabe que os serviços e produtos aqui estudados fazem parte desse conceito. Sugere-se por esse resultado que, apesar de os indivíduos saberem que os serviços e os produtos compartilhados são práticas comerciais diferentes das práticas tradicionais, o conceito de consumo compartilhado ainda não está sedimentado, sendo necessário o desenvolvimento de mais estudos.

Por fim, em resposta ao terceiro objetivo específico (verificar o relacionamento da geração y com os serviços e produtos disponibilizados por meio da prática de consumo colaborativo), foi apontado que os indivíduos pouco usam os serviços compartilhados, mas que eles conhecem a sua existência. Além disso, os resultados apontam a existência de quatro fatores analisados quando da utilização dos serviços: financeiro, comodidade, relacionamento e confiabilidade e socialmente responsável. Os fatores financeiro e socialmente responsável foram aqueles com maiores médias, demonstrando que a preocupação em gastar menos e em diminuir a poluição e diminuir a produção de lixo são questões consideradas quando os indivíduos pensam em usar serviços compartilhados. Para os indivíduos pesquisados, a redução de seus custos e a preocupação com o meio ambiente são os principais incentivos para o uso dos bens da economia compartilhada. Os fatores comodidade e relacionamento e confiabilidade também possuem influência, porém em menor peso.

Como limitação desta pesquisa, tem-se o fato da amostra por conveniência, o que não possibilita a generalização dos resultados e a limitação geográfica do estudo. Mesmo tendo sido respondido por pessoas fora de Fortaleza e região metropolitana, a participação de pessoas de outras cidades foi irrisória.

Por fim, sugere-se que mais estudos sobre o tema consumo colaborativo sejam desen- volvidos a fim de fortalecer o conceito e ampliar seu conhecimento, possibilitando novas formas de consumo e novas oportunidades para empresas e empreendedores. Sugere-se ainda uma pesquisa futura para investigar como as demais gerações (baby boomers, geração X e geração Z) percebem o consumo colaborativo, se eles consomem e qual a opinião sobre os serviços ofertados.

\section{REFERÊNCIAS}

ANDRADE, Helena da Gama Cerqueira; PINTO, Marcelo Resende. "O que é meu é seu ?!" - Seria o Consumo Colaborativo uma Inovação Social? In: ENCONTRO NACIONAL DE ESTUDOS DO CONSUMO, 7., 2014, Rio de Janeiro. Anais [...]. Rio de Janeiro, 2014.

ARRUDA, Hanna Rocha et al. Consumo colaborativo e valores pessoais: o caso da bicicleta compartilhada. Remark: Revista Brasileira de Marketing, v. 15, n. 5, out./dez. 2016.

BELK, R. Why Not Share Rather Than Own? Annals of the American Academy of Political and Social Science, v. 611 n. 1, p. 126-140, 2007.

BELK, R. W. You are what you can access: sharing and collaborative consumption online. Journal of Business Research, v. 67, n. 8, 2014.

BOTSMAN, R.; ROGERS, R. O que é meu é seu: como o consumo coletivo está mudando o nosso mundo. Porto Alegre: Bookman, 2011.

BUSSAB, Wilton. O.; MORETTIN, Pedro. A. Estatística Básica. São Paulo: Saraiva, 2002.

CHASE, Robin. Economia compartilhada: como as pessoas e as plataformas estão inventando a economia colaborativa e reinventando o capitalismo. São Paulo: HSM do Brasil, 2015.

CONSUMO COLABORATIVO. In: Dicioná- 
rio - Consumo Colaborativo. 2015. Disponível em: https://consumocolaborativo.cc/dicionario/. Acesso em: 26 jun. 2018.

DUTRA, Joel Souza. Gestão de carreiras na empresa contemporânea. São Paulo: Atlas, 2010.

DUTRA, Joel Souza; DUTRA, Tatiana Almendra. Gestão do processo sucessório. São Paulo: Atlas, 2016.

FERREIRA, Sara Raquel de Melo; LIMA, Talita Jeanny Dutra. Por que compartilhar? Um estudo sobre a economia compartilhada na cidade de Fortaleza. Revista de Gestão em Análise-REGEA, Fortaleza, v. 7, n. 2, p. 120-132, jul./dez. 2018.

FIELD, Andy. Descobrindo a estatística utilizando o SPSS. São Paulo: Bookman, 2009.

FIGUEIREDO FILHO, Dalson Brito; SILVA JÚNIOR, José Alexandre da. Visão além do alcance: uma introdução à análise fatorial. Revista Opinião Pública, Campinas, v. 16, n. 1, p. 160-185, jun. 2010.

GARBIN, Elisabete Maria. Cultur@s juvenis, identid@des e internet: questões atuais. Revista Brasileira de Educação, Rio de Janeiro, n. 23, maio/jun./jul./ago. 2003.

MAURER, A. M. et al. Yes, we also can! O desenvolvimento de iniciativas de consumo colaborativo no brasil. Revista de Administração e Contabilidade da Unisinos, v. 12, n. 1, p. 68-80, jan./mar. 2015.

MENEZES, Uiara Gonçalves de. Desenvolvimento sustentável e economia colaborativa: um estudo de múltiplos casos no brasil. 2016. Tese (Doutorado) - Universidade Federal do Rio Grande do Sul, Escola de Administração, 2016.

MONT, O. Institutionalisation of Sustainable
Consumption Patterns Based on Shared Use. Ecological Economics, v. 50, p. 135-153, 2004.

PIZZOL, Helena Oliveira Dall. Proposição de uma escala para mensuração do consume colaborativo: compreendendo o compartilhamento de bens e a sua relação com os valores pessoais. 2015. Dissertação (Mestrado) - Pontifícia Universidade Católica do Rio Grande do Sul, Faculdade de Administração, 2015.

RICHARDSON, Roberto Jarry et al. Pesquisa social: métodos e técnicas. São Paulo, Atlas, 2012.

ROCHA, Everardo. Cenas do Consumo: Notas, Ideias, Reflexões. Revista Semear, Rio de Janeiro, n. 6, 2002. Disponível em: http://www. letras.puc-rio.br/unidades\&nucleos/catedra/revista/6Sem_06.html. Acesso em: 26 jun. 2018.

RUDGE, Mariana et al. Geração Y: um estudo sobre suas movimentações, valores e expectativas. ReCaPe - Revista de Carreiras e Pessoas, São Paulo, v.7, n. 1, jan./fev./mar./abr. 2017.

SCHOR, J. Debating the sharing economy. Great Transition Iniciative, 2014. Disponível em: http:/greattransition.org/publication/debating-the-sharing-economy. Acesso em: 24 jul. 2018.

SOLOMON, Michael R. O comportamento do consumidor comprando, possuindo e sendo. Porto Alegre: Bookman, 2016.

TASCHNER, Gisela. Comunicação, sociedade e imaginários do consumo. Comunicação, mídia e consumo, São Paulo, v. 7, n. 20, p. 37-57, nov. 2010.

VELOSO, Elza, Fátima Rosa; DUTRA, Joel Souza; NAKATA, Lina Eiko. Percepção sobre carreiras inteligentes: diferenças entre as gerações Y, X e baby boomers. Rege - Revista de Gestão, n. 23, p. 88-98, 2016. 